13,14

\title{
Электрофизические свойства вдоль границы раздела двух полимерных пленок полиметилметакрилата
}

\author{
(C) А.Н. Лачинов ${ }^{1,2}$, Г.Р. Алтыншина ${ }^{1}$, Г.Ш. Байбулова ${ }^{2}$, М.Ф. Киан ${ }^{2}$, А.Р. Юсупов ${ }^{2}$ \\ ${ }^{1}$ Институт ффизики молекул и кристаллов Уфимского федерального исследовательского центра РАН, \\ Уфра, Россия \\ ${ }^{2}$ Башкирский государственный педагогический университет им. М. Акмуллы, \\ Уфра, Россия \\ E-mail: lachinov_a@mail.ru
}

Поступила в Редакцию 21 декабря 2020г.

В окончательной редакции 23 декабря 2020 г.

Принята к публикации 23 декабря 2020 г.

Проведены исследования проводимости вдоль границы раздела двух диэлектрических пленок субмикронной толщины. Представлены результаты сравнительного исследования электрофизических свойств отдельных пленок. В качестве диэлектрического материала был использован коммерческий полимер полиметилметакрилат. Исследования проводились по двухзондовой схеме методом вольт-амперных характеристик. Обнаружено аномальное по отношению к объемной увеличение проводимости. Установлено, что увеличение проводимости связано с возрастанием подвижности носителей заряда вдоль границы раздела до $140 \mathrm{~cm}^{2} / \mathrm{V} \cdot \mathrm{s}$. Проведено сравнение с известными из литературы аналогами, подчеркивается необходимость дополнительного анализа свойств контакта трехмерная/двумерная область.

Ключевые слова: полиметилметакрилат, диэлектрические пленки, граница раздела, подвижность.

DOI: 10.21883/FTT.2021.04.50724.266

\section{1. Введение}

В настоящее время ведется активный поиск и исследование материалов с высокой подвижностью носителей заряда. Это обусловлено с одной стороны традиционным направлением развития микро- и наноэлектроники, связанным с постоянным повышением тактовой частоты процессоров, перспективой создания твердотельной терагерцовой электроники [1]. Кроме того, возникли дополнительные требования к электронным материалам, которые должны помимо улучшения экономических характеристик обладать особыми механическими свойствами, обеспечивая реальную гибкость устройств [2]. В связи с этим проводится большой объем работ в направлении синтетических органических материалов (полимеров) [3] и принципиально новых электронных структур, например, функциональных диэлектриков, границы раздела которых способны к локализации электронного газа [4]. Одно из первых указаний на возможность аномальных электронных свойств границ раздела диэлектриков, по-видимому, содержится в работах $[5,6]$. Экспериментальное подтверждение этой гипотезы было сделано в работе [7] почти через 40 лет. В последующих работах [8]одно из предложенных объяснений основывалось на особенностях дипольного упорядочения вблизи границы раздела, так называемой идее поляризационной катастрофы. Позднее эта идея была реализована в принципиально другой органической системе - вдоль границы раздела двух диэлектрических полимеров класса полиариленфталидов, имеющих боковую функциональную группу с относительно большим дипольным моментом [9]. Особенности поверхностной поляризации тонких пленок этого типа полимеров были подтверждены позднее [10]. Предположение о важности боковой дипольной группы, обладающей определенной подвижностью относительно скелетной части цепи является ключевым условием для формирования поверхностнополяризованного слоя пленки полимера. Это же условие должно определять вероятность формирования квазидвумерного электронного состояния вдоль границы раздела двух диэлектрических полимерных пленок, характеризующегося высокой проводимостью, обусловленной аномально большой подвижностью носителей заряда. Однако, до сих пор исследование межфазной проводимости было ограничено узким выбором объектов из редкого класса полимеров полиариленфталидов. Очевидна важность изучения электронных свойств границы раздела двух органических диэлектриков на объектах, удовлетворяющих основным требованиям, перечисленным выше.

В связи с этим, целью настоящей работы явилось исследование электронных свойств вдоль границы раздела двух полимерных пленок, отвечающих нескольким критериям. В частности, полимер должен относиться к соединениям, в которых отсутствует сопряжение $\pi$-электронов, мономерное звено должно содержать дипольную группу, направленную под углом к скелетной части молекулы, быть растворимым и способным формировать качественные пленки. Кроме того, важным фактором для постановки этой работы явился выбор коммерчески доступного полимера. Так как в большинстве выполненных до сих пор работ по изучению свойств вдоль границ раз- 

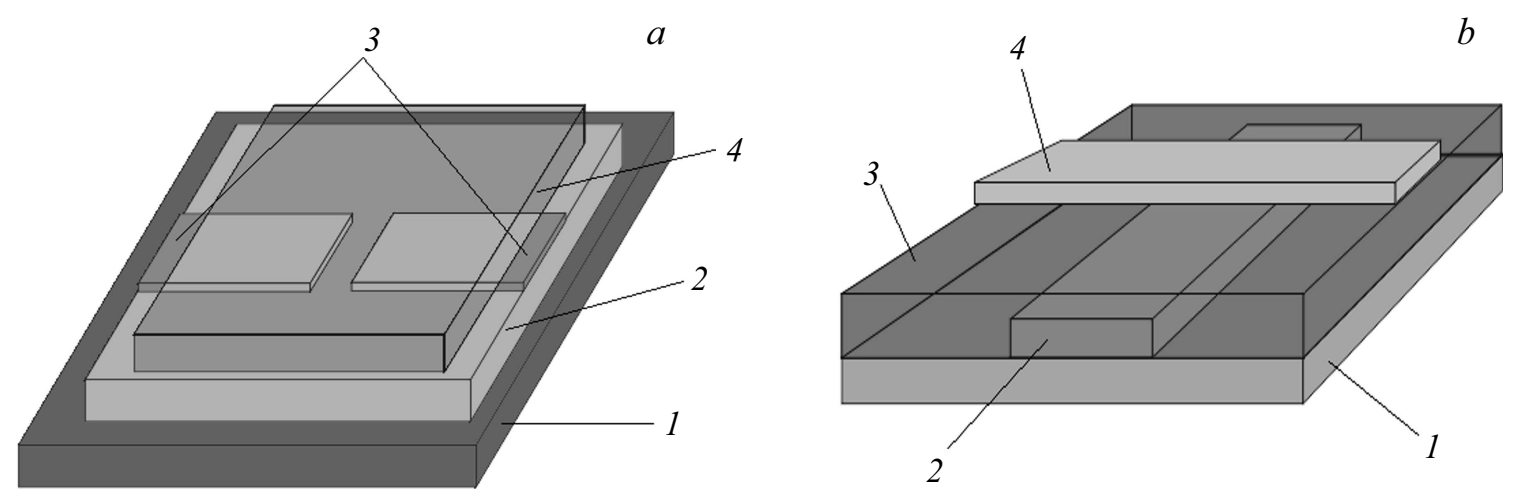

Рис. 1. a) Структура экспериментального образца, содержащего границу раздела: 1 - стеклянная пластина, 2 - первый слой пленки ПММА, 3 - медные электроды, 4 - второй слой пленки ПММА, $b$ ) структура образца вертикального типа $\mathrm{Cu} /$ полимер/In: 1 - стеклянная пластина, 2 - медный электрод, 3 - пленка ПММА, 4 - индиевый электрод.

$(6.660 \mu \mathrm{m} \times 6.660 \mu \mathrm{m} \times 983.4 \mathrm{~nm})(342 \times 342 \mathrm{pt})$

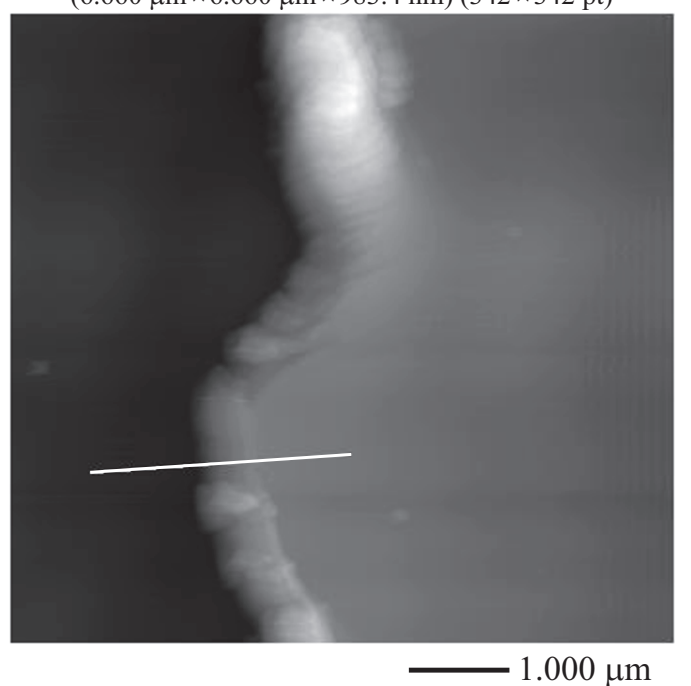

$a+b$

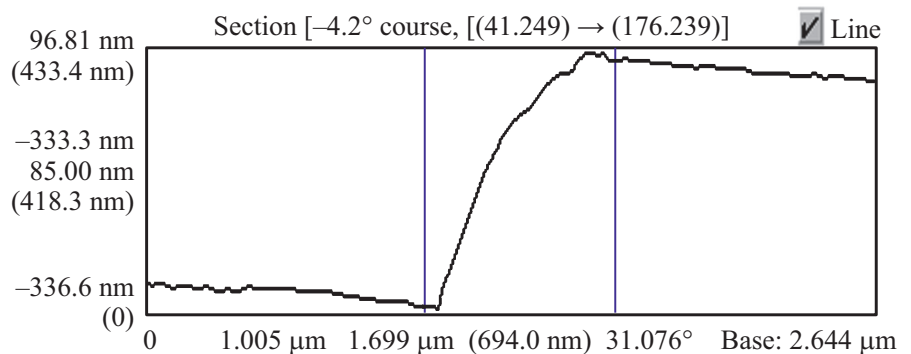

Рис. 2. Результаты атомно-силового контроля полимерных пленок. $a)$ Атомно-силовое изображение края пленки полиметилметакрилата, полученной из 7\% раствора в циклогексаноне. $b$ ) Рельеф вблизи края полимерного образца, полученный вдоль зондовой линии, показанной на рис. 2, a. Толщина пленки составляет $380 \pm 20 \mathrm{~nm}$, шероховатость пленки $\sim 0.4 \mathrm{~nm}$.

дела полимер/полимер были использованы коммерчески недоступные полимеры класса полиариленфталидов.

\section{2. Экспериментальная часть}

В качестве объекта исследования были использованы пленки коммерческого полиметилметакрилата (ПММА). ПММА является классическим примером аморфного диэлектрика, он имеет широкую запрещенную зону (более $5 \mathrm{eV}$ ) [11]. Дипольный момент полимера относительно большой. По разным оценкам от 1.36 до $1.5 \mathrm{D}$ [12]. Причем он ориентирован по направлению близкому к нормали к скелетной части макромолекулы.

Пленки полимеров отливались методом центрифугирования из растворов в циклогексаноне. Структура образцов представлена на рис. 1, $a, b$. Образцы формировались на поверхности стеклянных полированных пластин. Технологический маршрут изготовления образцов был следующим. На очищенную поверхность стеклянной пластины методом центрифугирования наносился первый слой полимера. Затем образец сушился при нормальных условиях в течение $40 \mathrm{~min}$. После чего выдерживался при температуре $90^{\circ} \mathrm{C}$ в течение $1 \mathrm{~h}$ для дальнейшего удаления остатков растворителя. На поверхность полимерной пленки наносились медные электроды методом вакуумного термодиффузионного напыления через теневую маску. Маска обеспечивала зазор между осажденными электродами порядка $50 \mu \mathrm{m}$. Далее наносился второй слой полимера с соблюдением процедур сушки, описанным выше.

В случае сэндвич структуры медный электрод осаждался на поверхность стеклянной пластины рис. $1, b$. Полимерный слой наносился методом центрифугирования из растворов ПММА в циклогексаноне концентрацией 5,7 и $10 \mathrm{wt} . \%$ соответственно. 
Электрод из индия наносился путем накатывания фольги на поверхность полимера. Площадь перекрытия электродов составляла $9 \mathrm{~mm}^{2}$. Толщину и однородность полимерных покрытий контролировали методом атомносиловой микроскопии. Изображение края полимерной пленки, нанесенной на стеклянную поверхность представлено на рис. 2.

Измерение электрофизических свойств проводили при комнатной температуре путем измерения вольтамперных характеристик (BAX) с использованием источника-измерителя Keithley 2400. Метод подробно описан в работе [13].

\section{3. Результаты и их обсуждение}

Прежде чем исследовать электронные свойства вдоль границы раздела ПММА/ПММА, были изучены вольтамперные характеристики отдельных полимерных пленок в структуре типа сэндвич-Cu/полимер/In в зависимости от их толщины. На рис. 3 представлены соответствующие зависимости.

Необходимо отметить нелинейный вид полученных BAX типичный для токов, ограниченных объемным зарядом. Кроме того, заметно влияние толщины полимерной пленки на проводимость и параметры носителей заряда. Использование электродов с разной работой выхода приводит к несимметричности ВАХ относительно смены направления, протекающего через образец тока, что хорошо видно на вставке рис. 3. Оценки разности высоты потенциального барьера находятся в хорошем согласии с известными данными по разности эффективных работ выхода меди $\mathrm{Cu}$.

Полученные зависимости хорошо аппроксимируются степенной функцией вида $I \sim k U^{n}$. В логарифмических координатах выделяются две области с $n \sim 1-$ омическая область, и при больших напряжениях с $n>1$. Инжекционная модель $[14,15]$ подобные зависимости связывает с тем, что в области малых напряжений перенос заряда осуществляется собственными носителями заряда. Превышение концентрации собственных носителей инжектированными из электрода происходит при определенном напряжении $U_{1}$. Потому в области малых напряжений выполняется закон Ома

$$
J \approx e n_{0} \mu \frac{U}{L}
$$

где $e$ - заряд электрона, $n_{0}$ - концентрация равновесных свободных зарядов, $\mu-$ подвижность электронов, $L$ - толщина пленки.

При превышении значения $U_{1}$ зависимость тока от приложенного напряжения видоизменяется

$$
J \approx \theta \varepsilon \varepsilon_{0} \mu \frac{U^{2}}{L^{3}}
$$

где $\theta-$ постоянная, характеризующая степень заполнения ловушек (в безловушечном режиме $\theta=1$ ), $\varepsilon-$

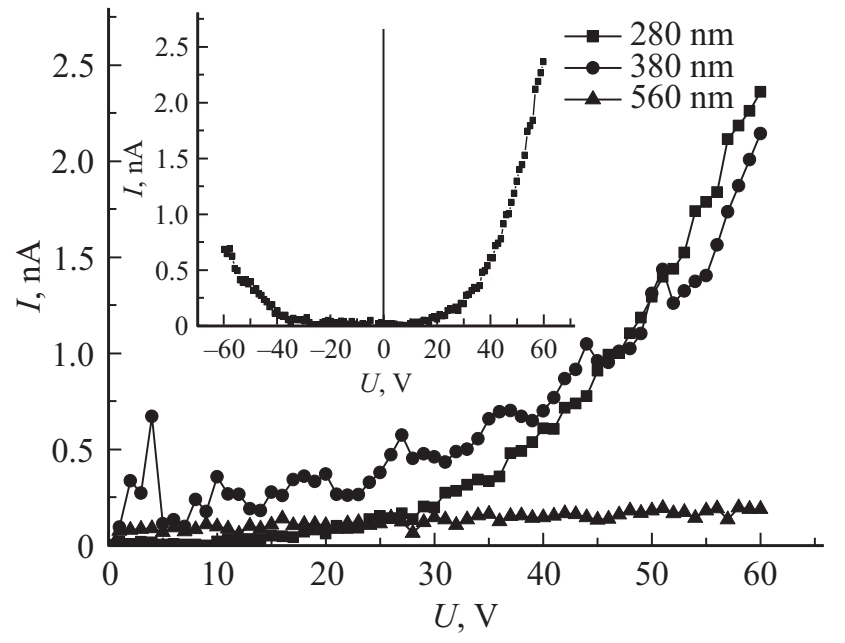

Рис. 3. Вольт-амперные характеристики структуры $\mathrm{Cu} /$ ПMМA/In. BAX при разных толщинах полимерной пленки: $280 \pm 20 \mathrm{~nm}, 380 \pm 20 \mathrm{~nm}, 560 \pm 20 \mathrm{~nm}$. На вставке представлена ВАX пленки толщиной $280 \mathrm{~nm}$ при двух направлениях тока.

диэлектрическая проницаемость, $\varepsilon_{0}$ - относительная диэлектрическая проницаемость $[14,15]$.

Анализ формул (1) и (2) позволяет оценить подвижность и концентрацию носителей заряда

$$
\begin{aligned}
& \mu=J L^{3} / \varepsilon \varepsilon_{0} U_{n}^{2}, \\
& n_{0}=\varepsilon \varepsilon_{0} U_{n} / e L^{2} .
\end{aligned}
$$

Анализ представленных на рис. 4 вольт-амперных характеристик позволил оценить подвижность и концентрацию носителей заряда. Пленки толщины $280 \pm 20 \mathrm{~nm}$ имеют подвижность равную $1.7 \cdot 10^{-11} \mathrm{~cm}^{2} / \mathrm{V} \cdot \mathrm{s}$ при концентрации носителей заряда $1.5 \cdot 10^{15} \mathrm{~cm}^{-3}$. А подвижность и концентрация в пленках толщиной $380 \pm 20 \mathrm{~nm}$ была равна $4.5 \cdot 10^{-11} \mathrm{~cm}^{2} / \mathrm{V} \cdot \mathrm{s}$ и $2.9 \cdot 10^{15} \mathrm{~cm}^{-3}$, соответственно. Но для пленок толщиной $600 \pm 20 \mathrm{~nm}$, отлитых из $10 \%$ раствора полимера, этим методом параметры носителей заряда оценить не удалось из-за малой величины проводимости и большой погрешности результатов оценок.

Таким образом, уменьшение толщины пленки ПММА приводит к некоторому увеличению подвижности носителей заряда. Концентрация носителей заряда мала и изменяется с толщиной слабо. Последнее можно объяснить тем, что этим методом оценивается концентрация собственных носителей заряда.

На рис. 4 представлены ВАХ, измеренные вдоль границы раздела ПММА/ПММА на образцах, представленных на рис. 1, $b$. В измеряемом интервале напряжений ВАХ имеет нелинейный вид. Очевидно, что при двухэлектродном методе измерений существенный вклад в проводимость границы раздела будут вносить контактные сопротивления, ограничивая протекающий ток. Однако надо отметить, что данные контакты могут 

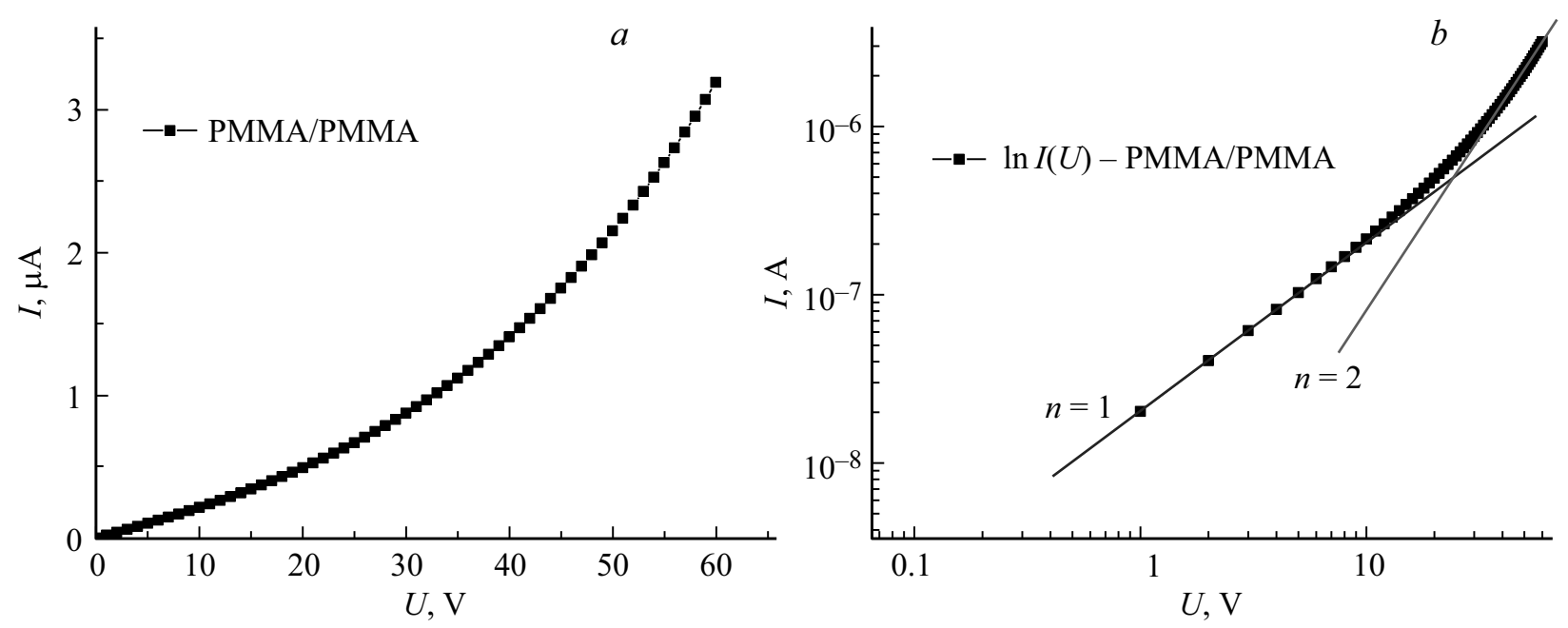

Рис. 4. Типичная вольт-амперная характеристика, измеренная вдоль границы раздела ПММА/ПММА - $(a)$, (b) BАХ в логарифмических координатах.

давать нетривиальный вклад в проводимость образцов, так как они представляют собой область перехода из трехмерного металла в квазидвумерную область. В связи с этим важно провести оценку параметров носителей заряда. С учетом нелинейности ВАХ в данной работе был применен формализм модели инжекционных токов аналогичный описанному выше [16-19].

Полученные значения подвижности носителей заряда вдоль границы раздела ПММА/ПММА оказались значительно выше параметров объемного переноса в поперечном направлении пленочных образцов (рис. 1, $a$, рис. 4). Например, подвижность носителей заряда составляет в среднем $140 \mathrm{~cm}^{2} / \mathrm{V} \cdot \mathrm{s}$, при низкой концентрация носителей заряда $5.45 \cdot 10^{12} \mathrm{~cm}^{-3}$. Низкая концентрация носителей заряда, полученная согласно (4) обусловлена тем, что она должна соответствовать равновесной концентрации, которая в ПММА ожидаемо низка.

Однако полученные значения подвижности носителей заряда являются нетривиально высокими. Даже в тонких субмикронных пленках ПММА, в которых наблюдалось некоторое повышение электропроводности с уменьшением толщины (рис. 3), подвижности носителей заряда значительно ниже.

В работах $[16,20]$ подобное несоответствие „объемных“ электронных свойств пленок полимеров и границ раздела двух полимерных пленок также отмечалось. Это различие объяснялось возникновением вдоль границы раздела коллективного электронного состояния, подобного квазидвумерному электронному газу, обнаруженному ранее вдоль границ раздела некоторых полярных диэлектриков, как органических $[21,22]$, так и неорганических $[7,23]$.

Общим для столь разных диэлектрических материалов, по-видимому, является то, что они имеют полярные группы, способные формировать поверхностный поляризованный слой. Одно из признанных объяснений возможности формирования квазидвумерного электронного газа использует модель поляризационной катастрофы, как следствие поверхностного взаимодействия поляризованных поверхностей.

У полиметилметакрилата такой группой является группа $\mathrm{COOCH}_{3}$ с дипольным моментом $\sim 1.9 \mathrm{D}$ [24]. Способность поляризации поверхности материалов на основе ПММА известна. Если сравнивать с полученными результатами, которые известны о свойствах вдоль границ раздела полидифениленфталида можно отметить следующее: качество поверхности субмикронных пленок ПММА ниже, в частности, шероховатость почти на два порядка выше. В связи с этим, все основные параметры носителей заряда (проводимость, подвижность и концентрация носителей заряда) в сравнении с ПДФ меньше. Тем не менее, они значительно превосходят параметры объемного материала ПММА, особенно это заметно в части подвижности, которая в двумерном случае возрастает на 9 порядков.

Безусловно, необычные электронные свойства границы раздела ПММА/ПММА требуют тщательного исследования. Необходимо отметить, что в настоящей работе обсуждается не истинная проводимость квазидвумерного слоя, а особенности проводимости вблизи контакта трехмерный материал (металлический электрод) двумерная область. На нетривиальные свойства такой системы контакта указывалось еще в работе [25]. Такая специфика связана с различием электронного энергетического спектра и со спецификой экранирования в низкоразмерных системах. Поэтому для определения истинной проводимости вдоль границы раздела необходимо использовать четырехзондовый метод.

Полученные результаты указывают на возможность привлечения двумерной модели формирования нового электронного состояния, вдоль границы раздела двух диэлектрических полимерных пленок ПММА для объяснения аномальной подвижности носителей заряда и, как следствие высокой проводимости системы. До сих пор 
подобные свойства наблюдались в довольно экзотических полимерных структурах. В данном случае работа выполнена на коммерческом полимере, что возможно откроет новые перспективы применения несопряженных полимеров в электронике.

\section{Благодарности}

Работа выполнялась при поддержке проекта „Зеркальные лаборатории“ Национального исследовательского университета „Высшая школа экономики“ и Башкирского государственного педагогического университета им. М. Акмуллы.

\section{Конфликт интересов}

Авторы заявляют, что у них нет конфликта интересов.

\section{Список литературы}

[1] K. Sengupta, T. Nagatsuma, D.M. Mittleman. Nature Electron. 1, 12, 622 (2018).

[2] X. Wang, A. Suwardi, S.L. Lim, F. Wei, J. Xu. Flexible Electron. 4, 1, 1 (2020).

[3] W.K. Schubert, P.M. Baca, S.M. Dirk, G.R. Anderson, D.R. Wheeler. Sandia National Laboratories. No. SAND20066723 (2006).

[4] J. Pereiroa, A. Petrovica, C. Panagopoulosa, I. Božović. Phys. Exp. 1, 208 (2011).

[5] V.L. Ginzburg. Phys. Lett. 13, 101 (1964).

[6] W.A. Harrison, E.A. Kraut, J.R. Waldrop, R.W. Grant. Phys. Rev. B 18, 4402 (1978).

[7] A. Ohtomo, H.Y. Hwang. Nature 427, 423 (2004).

[8] S. Thiel, G. Hammerl, A. Schmehl, C.W. Schneider, J. Mannhart. Science 313, 1942 (2006).

[9] R.M. Gadiev, A.N. Lachinov, V.M. Kornilov, R.B. Salikhov, R.G. Rakhmeev, A.R. Yusupov. Appl. Phys. Lett. 98, 173305 (2011).

[10] В.М. Корнилов, А.Н. Лачинов, Д.Д. Карамов, Ю.В. Кульвелис. ФТТ 58, 5, 1030 (2016).

[11] А.И. Драчев, С.3. Бумбан, И.В. Разумовская. ФТТ 33, 4, 1304 (1991).

[12] Л.Л. Бурштейн, Т.П. Степанова. Высокомолекуляр. соединения 8, 1, 71 (1971).

[13] Н.Ф. Мотт, Р.В. Генри. Электронные процессы в ионных кристаллах. ИЛ, М. (1950). 237 с.

[14] А.А. Бунаков, А.Н. Лачинов, Р.Г. Салихов. ЖТФ 73, 5, 104 (2003).

[15] М. Ламперт, П. Марк. Инжекционные токи в твердых телах. Мир, М. (1972). 416 с.

[16] Р.М. Гадиев, А.Н. Лачинов, В.М. Корнилов, Р.Б. Салихов, Р.Г. Рахмеев, А.Р. Юсупов. Письма в ЖЭТФ 90, 11, 821 (2011).

[17] H. Shirakawa, E.J. Louis, A.G. MacDiarmid et. al. J. Chem. Soc. Chem. Commun. I. 16, 578 (1977).

[18] C.K. Chiang, C.R. Fincher Jr, Y.W. Park et. al. Phys. Rev. Lett. 39, 17, 1098 (1977).

[19] Qin Wang, Jian-ling Li, Fei Gao, Wen-Sheng Li, KeZhong Wu, Xin-dong Wang. New Carbon Mater. 23, 3, 275 (2008).
[20] Р.М. Гадиев, А.Н. Лачинов, А.Ф. Галиев, Л.Р. Калимуллина, И.Р. Набиуллин. Письма в ЖЭТФ 100, 4, 276 (2014).

[21] J.R. Kirtley, J. Mannhart. Nature Mater. 7, 520 (2008).

[22] H. Alves, A.S. Molinari, H. Xie, A.F. Morpurgo, Nature Mater. 7, 574 (2008).

[23] N. Nakagawa, H.Y. Hwang, D.A. Muller. Nature Mater. 5, 204 (2006).

[24] В.А. Ломовской. Тонкие химические технологии 10, 3, 5 (2015).

[25] С.Г. Петросян, А.Я. Шик. ФТП 23, 1113 (1989).

Редактор К.В. Емцев 